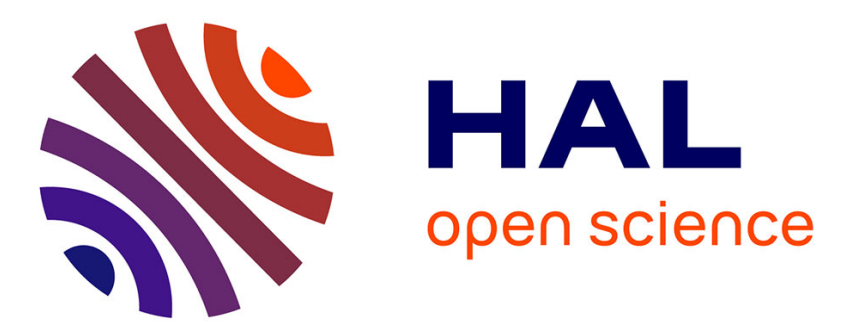

\title{
Solute diffusion in fractured porous media with memory effects due to adsorption
}

Jolanta Lewandowska, Jean-Louis Auriault, Sabrina Empereur, Pascale Royer

\section{To cite this version:}

Jolanta Lewandowska, Jean-Louis Auriault, Sabrina Empereur, Pascale Royer. Solute diffusion in fractured porous media with memory effects due to adsorption. Comptes Rendus Mécanique, 2002, 330 (12), pp.879 - 884. 10.1016/S1631-0721(02)01546-2 . hal-01715460

\author{
HAL Id: hal-01715460 \\ https://hal.science/hal-01715460
}

Submitted on 22 Feb 2018

HAL is a multi-disciplinary open access archive for the deposit and dissemination of scientific research documents, whether they are published or not. The documents may come from teaching and research institutions in France or abroad, or from public or private research centers.
L'archive ouverte pluridisciplinaire $\mathbf{H A L}$, est destinée au dépôt et à la diffusion de documents scientifiques de niveau recherche, publiés ou non, émanant des établissements d'enseignement et de recherche français ou étrangers, des laboratoires publics ou privés. 


\title{
Solute diffusion in fractured porous media with memory effects due to adsorption
}

\author{
Jolanta Lewandowska ${ }^{a}$, Jean-Louis Auriault ${ }^{b}$, Sabrina Empereur ${ }^{\text {a }}$, Pascale Royer ${ }^{b}$ \\ a Laboratoire LTHE, UJF, INPG, CNRS, IRD, UMR 5524, BP 53X, 38041 Grenoble cedex, France \\ b Laboratoire 3S, UJF, INPG, CNRS UMR 5521, BP 53X, 38041 Grenoble cedex, France
}

\begin{abstract}
Modelling of solute transport in fractured porous media is a subject of intensive research in many engineering disciplines, such as petroleum engineering, water resources management, civil engineering. Recent field and laboratory experiments show that, in presence of strong adsorption, the behaviour of solute penetrating into the fractured porous medium diverges from classical hypotheses, rendering impossible the adjustment of classical transport models. The aim of this paper is to develop a mathematical continuous model of solute transport, when strong adsorption of solute occurs on the grains of the porous matrix. The macroscopic model is obtained by upscaling the pore and the fracture behaviours, by using the multiple scale expansion method. We obtain a non-standard diffusion behaviour of solute which shows local non-equilibrium between transport in the fractures and in the porous matrix, as well as memory effects.
\end{abstract}

\section{Transport de soluté en milieu poreux fracturé : diffusion avec effets de mémoire due à l'adsorption}

Résumé La modélisation du transport de soluté dans un milieu poreux fracturé est un sujet d'actualité qui intéresse de nombreux domaines comme le génie pétrolier, la gestion des ressources en eau, le génie civil. De récentes recherches in situ et en laboratoire montrent qu'en présence d'une forte adsorption, le transport de soluté ne satisfait pas les modèles classiques. Le but de cette note est de présenter un modèle mathématique décrivant le transport de soluté quand une forte adsorption est présente sur les grains de la matrice poreuse. Le modèle macroscopique est obtenu par homogénéisation des comportements aux échelles des pores et des fractures, en utilisant la méthode des développements asymptotiques à échelles multiples. Nous obtenons ainsi un modèle non standard de diffusion qui met en évidence un non-équilibre local ainsi que des effets de mémoire.

E-mail addresses: Jolanta.Lewandowska@hmg.inpg.fr (J. Lewandowska); Jean-Louis.Auriault@hmg.inpg.fr (J.-L. Auriault); Pascale.Royer@hmg.inpg.fr (P. Royer). 


\section{Version française abrégée}

Nous recherchons un modèle mathématique décrivant le transport de soluté dans un milieu poreux fracturé, en présence d'une forte adsorption [1,2], sur les grains de la matrice poreuse. Le milieu présente trois échelles séparées $l, l_{p}$ et $L,(2)$. Il est doublement périodique, de périodes $\Omega_{m p}$ à l'échelle des pores et $\Omega$ à l'échelle des fractures. La période $\Omega$ des fractures est représentée sur la Fig. 1. L'espace poreux est noté $\Omega_{p}$, de surface $\Gamma_{p}$, et l'espace des fractures est $\Omega_{f}$, de surface $\Gamma$. La matrice microporeuse occupe $\Omega_{m}$ dans $\Omega$. Les porosités $n$ des pores et $\phi$ des fractures sont $\mathrm{O}(1)$. Le modèle est obtenu par changement d'échelles par la méthode des développements asymptotiques à échelle multiples [3-5]. La macroscopisation est conduite en deux étapes successives : obtention du modèle macroscopique de la matrice poreuse puis du modèle du milieu poreux fracturé.

Le transport de soluté dans la matrice poreuse est décrit par (3) et (4). Le temps caractéristique d'adsortion $T_{L}^{\text {ads }}$ est pris égal au temps macroscopique caractéristique de diffusion $T_{L}^{\text {dif }},(5)$, où l'indice $c$ indique des valeurs caractéristiques. Cela conduit à une longueur caractéristique d'adsorption $\alpha_{c}=L$. Le coefficient de retard $R_{d}=\alpha a_{s}=\mathrm{O}\left(\varepsilon^{-2}\right)$ (où $a_{s}=\mathrm{O}\left(l_{p}^{-1}\right)$ est la surface spécifique du milieu poreux) est très grand, ce qui denote une forte adsorption. En utilisant (5), on obtient la forme adimensionnelle de (3), (4) sous la forme (6), (7), où l'exposant «*» indique qu'il s'agit d'une grandeur adimensionnelle. L'homogénéisation est conduite comme en [4] et donne le modèle (8). Le tenseur $\mathbf{D}_{m}^{\mathrm{dif} *}\left(\mathbf{D}_{m}^{\mathrm{dif}}=D_{c} \mathbf{D}_{m}^{\mathrm{dif} *}=\right.$ $\mathrm{O}\left(D_{0}\right)$ ) est le tenseur effectif de diffusion de la matrice poreuse en l'absence d'adsorption. Une équation équivalente pour $C_{m}^{*}=n C_{p}^{*}$, où $n$ est la porosité, est donnée par (9). Enfin, sous forme dimensionnelle, le modèle macroscopique de l'écoulement dans la matrice poreuse est décrit par l'équation (10). La mise sous la forme d'un bilan de soluté (11) fait apparaître un tenseur effectif de diffusion en présence d'adsorption $\mathbf{D}_{m}^{\text {dif-ads }}=R_{d}^{-1} \mathbf{D}_{m}^{\text {dif }}$.

La description locale dans les fractures est donnée par (12) qui se met sous la forme adimensionnelle (13). Les conditions aux limites sur $\Gamma$ sont la continuité des concentrations (14) et la continuité des flux (15) associée aux équations (10) et (12). Les conditions aux limites adimensionnelles sur $\Gamma$ sont (16) et (17). Le problème local à l'échelle des fractures est ainsi décrit par les équations (9), (13), (16), (17). Il est semblable au problème de diffusion dans les matériaux composites à grand contraste de propriétés, [7-9]. Le modèle macroscopique, cf. [10] pour les détails, est sous la forme (18), où $\phi_{f}=\Omega_{m} / \Omega$ est la porosité des fractures, $D_{f}^{\text {dif* }}$ est le tenseur effectif de diffusion dans les fractures et $K(\tau)$, défini par (22), est une fonction mémoire déterminée par le problème aux limites (19), (20) dont la solution est (21).

\section{Introduction}

We develop a mathematical continuous model of solute transport in fractured porous media, when diffusion is present in both the fractures and the porous matrix, and when strong adsorption of solute occurs on the grains of the porous matrix. Strong adsorption coefficients are reported in many references, e.g., [1,2]. Strong adsorption is addressed by letting the characteristic time of adsorption to be equal to the characteristic macroscopic time of diffusion (see part 2). We assume the double porosity medium to be doubly periodic, i.e., it is periodic at the pore scale and at the fracture scale (see Fig. 1 for the fracture period). The porosities $n$ of the porous matrix and $\phi$ of the fractures are $\mathrm{O}(1)$. We have to deal with three different scales: the microscopic scale $l_{p}$ (the dimension of the porous period at the pore scale $\Omega_{p m}$ ), the mesoscopic scale $l$ (the dimension of the fractured period $\Omega$ ), and the macroscopic scale $L$ (the dimension of the macroscopic domain). If there exists a scale separation between each of the three scales, $l_{p} \ll l \ll L$, then we have a double porosity structure, i.e., a fractured porous medium. In this case three non-dimensional space variables can be defined

$$
\mathbf{z}=\frac{\mathbf{X}}{l_{p}}, \quad \mathbf{y}=\frac{\mathbf{X}}{l}, \quad \mathbf{x}=\frac{\mathbf{x}}{L}
$$




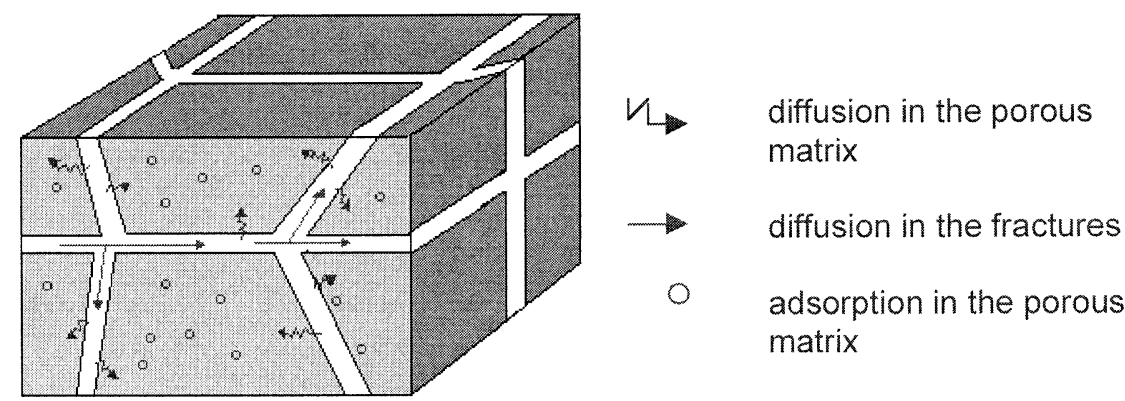

Figure 1. A period of the fractured porous medium: the solute transport mechanisms are diffusion and adsorption in the porous matrix.

Figure 1. Une période du milieux poreux fracturé : le soluté diffuse dans les fractures et les pores et est adsorbé par la matrice poreuse.

where $\mathbf{X}$ is the physical space variable. Therefore, any problem can be regarded with respect to three dimensionless spatial coordinates systems. For the sake of simplicity, we assume equal separations of scales

$$
\frac{l_{p}}{l}=\frac{l}{L}=\varepsilon \ll 1
$$

The fractured porous medium is assumed to be rigid and fully saturated by an incompressible fluid (water) at rest. The adsorption on the solid surface of the pores is assumed strong, linear, reversible and instantaneous. The upscaling is obtained by using the method of homogenization of periodic structures by formal asymptotic expansions [3,4]. We follow the methodology presented in [5]. The main advantage of this homogenization method is that it makes possible to analyze the competitive and interacting phenomena at different spatial and temporal scales and to capture the predominating macroscopic effects. We proceed by successively determine the overall behaviours of the porous matrix and then the fractured medium.

\section{Overall solute transport in the porous matrix}

The transport of solute by diffusion in the pores of the porous medium is given by

$$
\frac{\partial C_{p}}{\partial t}-\nabla_{X}\left(D_{0} \nabla_{X} C_{p}\right)=0 \text { in } \Omega_{p}
$$

where $C_{p}$ is the solute concentration in the pore space $\Omega_{p}$ of $\Omega_{p m}, D_{0}$ is the coefficient of molecular diffusion of solute in water and $t$ is time. At the interface $\Gamma_{p}$ between solid and liquid adsorption of solute takes place, which is written

$$
-\mathbf{N} \cdot D_{0} \nabla_{X} C_{p}=\alpha \frac{\partial C_{p}}{\partial t} \quad \text { on } \Gamma_{p}
$$

where $\mathbf{N}$ is the unit outward vector to $\Omega_{p}$, normal to $\Gamma_{p}$. The length $\alpha$ relates the flux adsorbed by the unit surface of the solid to the time variations of the solute concentration and expresses the intensity of adsorption [6]. In the analysis, the time of diffusion at the macroscopic scale $L$ is taken as the characteristic time $T_{c}$ (the time of observation of solute transport). It is also assumed that the characteristic time of adsorption $T_{L}^{\text {ads }}$ is equal to the characteristic time $T_{L}^{\text {dif }}$ of diffusion, which is written

$$
T_{c}=T_{L}^{\mathrm{dif}}=\frac{L^{2}}{D_{c}}=T_{L}^{\mathrm{ads}}=\frac{\alpha_{c} L}{D_{c}}
$$

where $\alpha_{c}$ and $D_{c}$ are characteristic values of $\alpha$ and $D_{0}$, respectively. Note that as a result of (5), we have $\alpha_{c}=L$. Therefore, the retardation coefficient $R_{d}=\alpha a_{s}=\mathrm{O}\left(\varepsilon^{-2}\right)\left(a_{s}=\mathrm{O}\left(l_{p}^{-1}\right)\right.$ is the specific surface of the porous medium), is high which shows a strong adsorption. The dimensionless numbers present in (3) 
and (4) are evaluated by using (5). It results in the following dimensionless forms of (3) and (4), where the superscript ' $*$ ' denotes a dimensionless quantity

$$
\begin{aligned}
& \varepsilon^{4} \frac{\partial C_{p}^{*}}{\partial t^{*}}-\nabla_{z}^{*}\left(D_{0}^{*} \nabla_{z}^{*} C_{p}^{*}\right)=0 \text { in } \Omega_{p} \\
& -\mathbf{N} \cdot D_{0}^{*} \nabla_{z}^{*} C_{p}^{*}=\varepsilon^{2} \alpha^{*} \frac{\partial C_{p}^{*}}{\partial t^{*}} \quad \text { on } \Gamma_{p}
\end{aligned}
$$

The results of the upscaling process is a diffusion-adsorption equation for the non-dimensional concentration $C_{p}^{*}$ (for details, see [6], where a similar problem is addressed)

$$
R_{d}^{*} \frac{\partial C_{p}^{*}}{\partial t^{*}}-\nabla_{y}^{*}\left(\mathbf{D}_{m}^{\mathrm{dif} *} \nabla_{y}^{*} C_{p}^{*}\right)=0 \quad \text { in } \Omega_{p m}
$$

where $C_{p}^{*}$ is now the first order approximation of the solute concentration (mass of the solute in the unit volume of water in the pores). Tensor $\mathbf{D}_{m}^{\text {dif }}=D_{c} \mathbf{D}_{m}^{\text {dif } *}=\mathrm{O}\left(D_{0}\right)$ is the effective matrix diffusion tensor in absence of adsorption [3]. The non-dimensional retardation factor is $R_{d}^{*}=\alpha^{*} a_{s}^{*}=\mathrm{O}(1)$. An equation similar to (8) can be written for the non-dimensional matrix mass concentration $C_{m}^{*}=n C_{p}^{*}$, where $n$ is the matrix porosity

$$
R_{d}^{*} \frac{\partial C_{m}^{*}}{\partial t^{*}}-\nabla_{y}^{*}\left(\mathbf{D}_{m}^{\mathrm{dif} *} \nabla_{y}^{*} C_{m}^{*}\right)=0 \quad \text { in } \Omega_{p m}
$$

The corresponding dimensional equation is

$$
R_{d} \frac{\partial C_{m}}{\partial t}-\nabla_{X}\left(\mathbf{D}_{m}^{\mathrm{dif}} \nabla_{X} C_{m}\right)=0, \quad R_{d}=\mathrm{O}\left(\varepsilon^{-2}\right) \text { in } \Omega_{p m}
$$

This latter equation can be put in the form of a balance equation for $C_{m}$

$$
\frac{\partial C_{m}}{\partial t}-\nabla_{X}\left(\mathbf{D}_{m}^{\mathrm{dif}-\mathrm{ads}} \nabla_{X} C_{m}\right)=0 \quad \text { in } \Omega_{p m}
$$

where tensor $\mathbf{D}_{m}^{\text {dif-ads }}=R_{d}^{-1} \mathbf{D}_{m}^{\text {dif }}$ stands for the effective diffusion tensor of the porous matrix in presence of adsorption.

\section{Overall solute transport in the fractured porous medium}

The problem of solute diffusion in the fractures can be formulated as follows

$$
\frac{\partial C_{f}}{\partial t}-\nabla_{X}\left(D_{0} \nabla_{X} C_{f}\right)=0 \quad \text { in } \Omega_{f}
$$

where $C_{f}$ is the local solute concentration in the fractures domain $\Omega_{f}$ of the fractured period $\Omega_{l}$. When using $\mathbf{y}$ as the dimensionless space variable and estimate (5), the dimensionless form of (12) becomes

$$
\varepsilon^{2} \frac{\partial C_{f}^{*}}{\partial t^{*}}-\nabla_{y}^{*}\left(D_{0}^{*} \nabla_{y}^{*} C_{f}^{*}\right)=0
$$

The conditions at the interface $\Gamma$ between the homogenized porous matrix and the fractures are the continuity condition of concentrations

$$
C_{f}=C_{p}=\frac{C_{m}}{n} \quad \text { on } \Gamma
$$

and the continuity condition of fluxes associated to Eqs. (11) and (12)

$$
\mathbf{N} \cdot D_{0} \nabla_{X} C_{f}=\mathbf{N} \cdot \mathbf{D}_{m}^{\text {dif-ads }} \nabla_{X} C_{m} \quad \text { on } \Gamma
$$

Finally, the dimensionless forms of the interface conditions are

$$
\begin{aligned}
& C_{f}^{*}=C_{p}^{*}=\frac{C_{m}^{*}}{n} \quad \text { on } \Gamma \\
& \mathbf{N} \cdot D_{0}^{*} \nabla_{y} C_{f}^{*}=\varepsilon^{2} \mathbf{N} \cdot \mathbf{D}_{m}^{\mathrm{dif}-\mathrm{ads} *} \nabla_{y}^{*} C_{m}^{*} \quad \text { on } \Gamma
\end{aligned}
$$




\subsection{Macrotransport behaviour}

The method applied to derive the macroscopic model is again the homogenization technique for periodic structures by formal asymptotic expansions. It can be noticed that the local problem (9), (13), (16), (17) is formally similar to the diffusion problem in a composite of contrasted characteristics, presented in the literature (see for example [7-9]). The homogenized macroscopic model for the fractured porous medium is written as follows (see [10]), at the first order of approximation

$$
\Phi_{f} \frac{\partial C_{f}^{*}}{\partial t^{*}}+\int_{-\infty}^{t^{*}} K^{*}\left(t^{*}-\tau\right) \frac{\partial^{2} C_{f}^{*}}{\partial \tau^{2}} \mathrm{~d} \tau-\nabla_{x}^{*}\left(D_{f}^{\mathrm{dif} *} \nabla_{x}^{*} C_{f}^{*}\right)=0
$$

where $C_{f}^{*}$ is the first order approximation of the macroscopic mass concentration in the fractures, $\phi_{f}=$ $\Omega_{f} / \Omega$ is a volumetric fraction of fractures in the period, $D_{f}^{\text {dif* }}$ is the non-dimensional effective diffusion tensor in the fracture domain and $K(\tau)$ is a memory function that is to be determined from the solution of the local problem for the particular porous matrix geometry in consideration (see [10] or [7-9]) for a similar type of problem). The solute transport in the matrix domain is governed by the following equations

$$
R_{d}^{*} \frac{\partial C_{m}^{*}}{\partial t^{*}}-\nabla_{y}^{*}\left(D_{m}^{\mathrm{dif} *} \nabla_{y}^{*} C_{m}^{*}\right)=0 \quad \text { in } \Omega_{m}
$$

where $\Omega_{m}$ is the part of $\Omega$ occupied by the microporous matrix, and

$$
C_{m}^{*}=n C_{f}^{*} \quad \text { on } \Gamma
$$

The solution can be put in the form

$$
C_{m}^{*}=\int_{-\infty}^{t^{*}} k^{*}\left(t^{*}-\tau\right) C_{f}^{*} \mathrm{~d} \tau
$$

The memory function $K$ is then defined by

$$
K^{*}=\frac{1}{\Omega} \int_{\Omega_{m}} k^{*} \mathrm{~d} \Omega
$$

The integral form in Eq. (18) exhibites a coupling between the solute transport in the fractures and in the matrix.

\section{Conclusion}

In this paper a nonstandard diffusion model is presented for solute transport in fractured porous media in presence of strong adsorption. The model proposed is a one equation diffusion model with memory effects due to adsorption of the solute in the porous matrix. The adsorption causes the diffusion in the matrix to be retarded with respect to the diffusion in the fractures. This is a source of local non-equilibrium, and consequently of long-tail behaviour.

Acknowledgement. The financial support of the PNRH program "Transferts complexes en milieu poreux et resources en eau" of the INSU-CNRS is greatly acknowledged.

\section{References}

[1] C.A.J. Appelo, D. Postma, Geochemistry, Groundwater and Pollution, Balkema, 1994, pp. 339-349.

[2] U.S. Environmental Protection Agency: Guide for Industrial Waste Management, Appendices 7a-7c, http://www. epa.gov/epaoswer/non-hw/industd/guide/index.htm.

[3] É. Sanchez-Palencia, Comportement local et macroscopique d'un type de milieux physiques hétérogènes, Int. J. Engrg. Sci. 12 (1974) 331-351.

[4] A. Bensoussan, J.-L. Lions, G. Papanicolaou, Asymptotic Analysis for Periodic Structures, North-Holland, 1978.

[5] J.-L. Auriault, Heterogeneous medium. Is an equivalent macroscopic description possible?, Int. J. Engrg. Sci. 29 (7) (1991) 785-795.

[6] J.-L. Auriault, J. Lewandowska, Homogenization analysis of diffusion and adsorption macrotransport in porous media: macrotransport in the absence of advection, Geotechnique 43 (3) (1993) 457-469. 
[7] J.-L. Auriault, Effective macroscopic description for heat conduction in periodic composites, J. Heat Mass Transfer 26 (6) (1983) 861-869.

[8] J.-L. Auriault, R. Royer, Double conductivity media: a comparison between phenomenological and homogenization approaches, Int. J. Heat Mass Transfer 36 (10) (1993) 2613-2621.

[9] J.-L. Auriault, J. Lewandowska, Non-Gaussian diffusion modeling in composite porous media by homogenization: tail effect, Transport in Porous Media 21 (1995) 47-70.

[10] S. Empereur, Étude de l'écoulement d'eau et du transport de polluants dans les milieux poreux fracturés par la technique d'homogénéisation en tenant compte de l'adsorption, DEA report, 2001. 